\title{
Beobachtungen der Euterpe an der Wiener Sternwarte.
}

\begin{tabular}{|c|c|c|c|}
\hline 1858 & M. Wien. Zt & & $\alpha$ \\
\hline Febr. 11 & $12^{\mathrm{h}} 10^{\mathrm{m}} 19^{\mathrm{s}}$ & $9^{b} 37^{n}$ & $10^{8} 21$ \\
\hline 12 & $12 \quad 5 \quad 24$ & 936 & 10,93 \\
\hline 17 & $11 \quad 40 \quad 53$ & 931 & 18,37 \\
\hline 18 & $\begin{array}{lll}11 & 36 & 1\end{array}$ & 930 & 22,06 \\
\hline 23 & 111155 & 925 & 55,34 \\
\hline 24 & 11710 & 925 & 5,66 \\
\hline 26 & $10 \quad 57 \quad 42$ & 923 & 30,45 \\
\hline
\end{tabular}

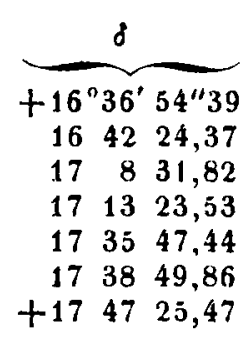

\begin{tabular}{rrr}
$\Delta \alpha$ & \multicolumn{1}{c}{$\Delta \delta$} & \multicolumn{1}{c}{ Par. } \\
$-9^{\circ} 46$ & $+38^{\prime \prime} 3$ & $+4^{\prime \prime} 15$ \\
8,81 & 36,1 & 4,13 \\
8,30 & 29,3 & 4,03 \\
8,02 & 33,3 & 4,01 \\
7,00 & 22,8 & 3,89 \\
6,76 & 22,5 & 3,87 \\
$-6,38$ & $+21,1$ & $+3,82$
\end{tabular}

Diese Positionen sind von Herrn Assistenten $M$. Allé an den lichten Fäden des Meridiankreises bestimmt,' die Differenzen B-R gegen das Berliner Jahrbuch genommen.

Wien 1858 Febr. 27.

\section{Littron.}

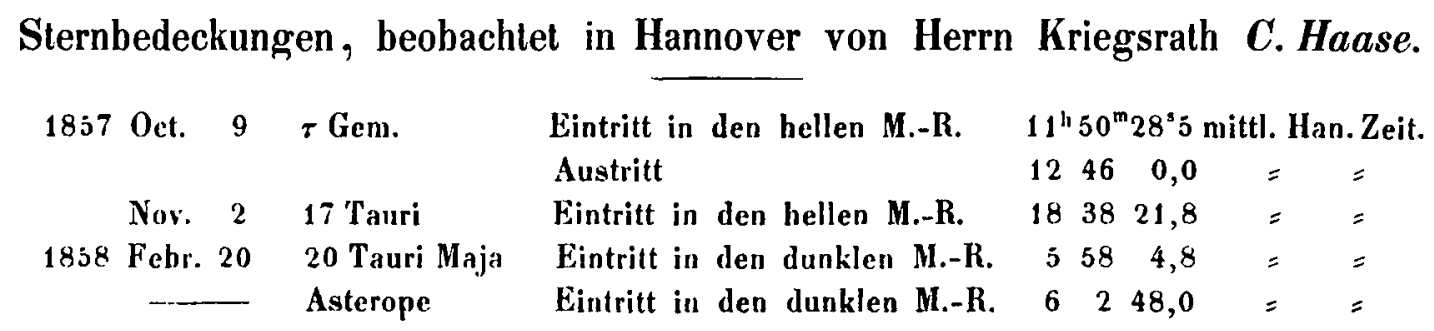

Parabolische Elemente des Cometen II. 1858, von Hern Dr. Schjellerup.

Aus den Beobachtungen Bonn März 8, Altona März 11 und Kopenhagen März 17 habe ich nachstehende Elemente abgeleitet :

$$
\begin{aligned}
& T=\text { Mai 1,63347 Greenw. M. T. } \\
& \left.\begin{array}{rl}
\Omega & =107^{\prime \prime} 14^{\prime} 49^{\prime \prime} \\
\pi & =294 \text { 5 } 39
\end{array}\right\} \text { M. Aeq. März 1,0 } \\
& i=123516 \\
& \log q=9,78896 \\
& \text { Bewegung direct. }
\end{aligned}
$$

Es scheint darnach, dass auch dieser Comet ein periodischer ist, wenigstens stimmen obige vorläufige Elemente mit denen des dritten von 1819. Der mittlere Ort wird nicht sehr gut dargestellt; vielleicht rührt dieses von der Ellipticität der Bahn her.

Die Beohachtung am $17^{\text {ten März: }}$ $16^{\mathrm{l}} 22^{\mathrm{\prime \prime}} 37^{\mathrm{s}} \mathrm{m}$.Z.Kopenhg. $\alpha=275^{\circ} 40^{\prime} 14^{\mu} 2 \quad \delta=-2^{\circ} 4^{\prime} 35^{A} 9$

Kopenhagen 1858 März 19.
Schjellerup.

\section{Fernerẻ Beobachtungen der Sonnenfinsterniss 1858 März 15:}

\section{In Kiel, mitgetlieilt von Herrn Professur Weyer.}

Die Sonnentinsterniss geschah hier zu Anfange unter dichten Wolken, von deren Zertheilung auch die Helligkeit und der Gang der Temperatur ahhing, so dass es zur Zeit der Mitte der Sonnenfinsterniss heller und wärmer war, als vorher.

Das Ende der Finsterniss beobachteten wir wie folgt:

$$
\begin{array}{rlr}
\text { März } 15 & 3^{11} 7^{m} 7^{\mathrm{s}} 8 \text { mittl. Zt. Kiel Prof. Krrsten } \\
15 & 3699,9==0 \\
\text { Weyer }
\end{array}
$$

Prof. Karsten hält es für müylich, sich un eine Minute heim Ablesen des Chronometers versehen zu haben.

Die Zeithestimmung beruht auf Sonnenböhen, nit einem Spiegelsextanten genessen, der die Polhöhe sehr nahe wiedergiebt, also mit kcinen bedeutenden eigenthümlichen Febler behaftet ist. - Correspondirende Hühen zu beobachten wurde durch die Witterung verhindert.
Kiel 1858 März 21.
G. Weyer. 